\title{
Posibilidades y limitaciones de una propuesta de aplicación de la metodología del aula invertida con el uso de TDIC en la enseñanza de las matemáticas
}

\author{
Braian Lucas Camargo Almeida ${ }^{1}$ \\ braian_almeida@hotmail.com \\ https://orcid.org/0000-0001-5237-730X \\ Janecler Aparecida Amorin Colombo ${ }^{2}$ \\ janecler.aac@gmail.com \\ https://orcid.org/0000-0002-7729-9501 \\ ${ }^{1}$ Universidade Federal do Paraná (UFPR, Brasil) \\ ${ }^{2}$ Universidade Tecnológica Federal do Paraná (UTFPR, Brasil)
}

Recibido: 31/05/2020 Aceptado: 06/07/2020

\begin{abstract}
Resumen
El propósito de este artículo fue sintetizar las posibilidades y limitaciones del uso de la metodología del Aula Invertida en las clases de matemáticas para las clases en el octavo grado de la escuela primaria. Con este fin, se utilizó la producción y aplicación de una propuesta de enseñanza que implica el uso de las TDIC. El estudio se justificó debido a la escasez de trabajos relacionados con el aula invertida en el escenario brasileño, sobre todo a la enseñanza de las matemáticas en la Educación Básica. Los datos recopilados se sometieron a análisis de contenido, según Bardin (2006), lo que permitió identificar los entendimientos expresados por los participantes de la investigación. Entre las posibilidades encontradas, destacan la participación e interés de los alumnos; el uso de video clases; Aprendizaje colaborativo y una mejor comprensión del contenido a través de presentaciones de tareas. En cuanto a los límites es evidente la falta de madurez de algunos estudiantes; poco tiempo de clase para algunas etapas y la falta de adaptación de los estudiantes a las tareas semanales en línea como una forma de evaluación. Además, se observó que la propuesta muestra una adaptabilidad potencial a otro contenido matemático y se hizo evidente la importancia e influencia de las TDIC como medio de enseñanza, aprendizaje y evaluación dentro de las etapas de la propuesta.
\end{abstract}

Palabras clave: TDIC en la enseñanza de las matemáticas; Metodologías de aprendizaje activo; Aula invertida.

\section{Possibilidades e limitações de uma proposta de aplicação da metodologia da sala de aula invertida com o uso de TDIC no ensino de matemática}

\begin{abstract}
Resumo
O presente artigo teve como finalidade sintetizar as possibilidades e limitações da utilização da metodologia Sala de Aula Invertida em aulas de matemática para turmas do $8^{\circ}$ ano do Ensino Fundamental. Para tal, utilizou-se a produção e aplicação de uma proposta de ensino envolvendo o uso de TDIC. O estudo justificou-se devido à escassez de trabalhos relacionados à sala de aula invertida no cenário brasileiro, no que tange o ensino de matemática na Educação Básica. Os dados coletados foram submetidos à análise de conteúdo, conforme Bardin (2006), o que possibilitou identificar as compreensões manifestadas pelos participantes da pesquisa. Entre as possibilidades encontradas, destaca-
\end{abstract}


se a participação e interesse dos alunos; o uso das videoaulas; a aprendizagem de forma colaborativa e melhor compreensão dos conteúdos através das apresentações de tarefas. Já em relação aos limites, evidencia-se a falta de maturidade de alguns alunos; o tempo de aula curto para algumas etapas e a falta de adaptação dos alunos em relação aos trabalhos on-line semanais como forma de avaliação. Além disso, percebeu-se que a proposta mostra potencial adaptabilidade a outros conteúdos matemáticos e ficou clara a importância e influência das TDIC como meios de ensino, aprendizagem e avaliação dentro das etapas da proposta.

Palavras-chave: TDIC no ensino de matemática; Metodologias ativas de aprendizagem; Sala de aula invertida.

\title{
Possibilities and limitations of a proposal to apply the methodology flipped classroom with the use of TDIC in the teaching of mathematics
}

\begin{abstract}
The purpose of this article was to summarize the possibilities and limitations of using the Flipped Classroom methodology in mathematics classes for classes in the 8th grade of elementary school. To that, the production and application of a teaching proposal involving the use of TDIC was used. The study was justified due to the scarcity of works related to the Flipped Classroom in the brazilian scenario, regarding the teaching of Mathematics in Basic Education. The collected data were submitted to content analysis, according to Bardin (2006), which made it possible to identify the understandings expressed by the research participants. Among the possibilities found, students participation and interest stand out; the use of video classes; learning collaboratively and better understanding of content through task presentations. Regarding the limits, it is evident the lack of maturity of some students; short class time for some stages and students' lack of adaptation to weekly online assignments as a form of assessment. In addition, it was noticed that the proposal shows potential adaptability to other mathematical content and it became clear the importance and influence of TDIC as means of teaching, learning and evaluation within the stages of the proposal.
\end{abstract}

Keywords: TDIC in the teaching of mathematics; Active learning methodologies; Flipped classroom.

\section{Introdução}

Nos últimos anos, o grande desafio das instituições de ensino têm sido a busca crescente por práticas pedagógicas inovadoras capazes de oportunizar uma formação personalizada, que possibilite desenvolver a autonomia dos alunos sobre o seu aprendizado. Moran (2015, p. 18) cita as metodologias ativas de aprendizagem como ponto de partida "para processos mais avançados de reflexão, de integração cognitiva, de generalização, de reelaboração de novas práticas”, pois uma das maneiras do aprendizado efetivo ocorrer se dá a partir de problemas e situações reais. Muitas "estratégias têm sido usadas para promover a aprendizagem ativa, como a aprendizagem baseada na pesquisa, o 
uso de jogos, a aprendizagem baseada em problemas (ABP)" e a Sala de Aula Invertida (Valente, 2014, p. 82).

Neste artigo tratamos de uma proposta de ensino pautada na Sala de Aula Invertida. Esta estratégia propõe a inversão da lógica da sala de aula, permitindo que os alunos tenham contato com o conteúdo antes da aula presencial, em casa. Ou seja, a aula começa com a tarefa de casa. Pode ser através de um vídeo, um game educativo ou outros recursos digitais. Desta forma, o aluno já adquire um conhecimento prévio sobre o conteúdo e utiliza a sala de aula física para tirar as dúvidas e fixar o que aprendeu, tendo o suporte dos colegas e do professor, que passa a ser um mediador do conhecimento adquirido.

Segundo Moretto, "é uma metodologia que motiva atividades colaborativas, em grupo, a criação de projetos e promove o envolvimento dos alunos" (2015). Neste sentido, Freitas corrobora, ao afirmar que:

A utilização do método de ensino da flipped classroom, ou Sala de Aula Invertida, representa a oportunidade da quebra de um paradigma presente no modelo tradicional, no qual o tempo reservado para a interação com o conteúdo é fixo e o tempo para sua compreensão é variável. No Ensino Médio, a maior parte do ensino em sala de aula se dá através de aulas expositivas onde na maioria das vezes a atuação do aluno é passiva frente ao conteúdo estudado. Devido à extensão do currículo, o período que esse educando tem para praticar o conteúdo acontece principalmente em casa na forma de exercícios, suprimindo do ambiente escolar o tempo de discussão e compreensão da matéria, dificultando para o professor a identificação das lacunas desse aprendizado. (2015, p. 2).

Concordamos com essa perspectiva apontada por Freitas e apostamos em modelos não convencionais para o ensino e aprendizagem da matemática, que priorizam a participação ativa do estudante e aumentam o tempo do espaço escolar para priorizar atividades práticas de compreensão e de resolução de problemas, bem como para o atendimento personalizado do aluno. Com este propósito e com o intuito de compreender como os agentes envolvidos neste processo percebem tais mudanças a Proposta de Aplicação da Sala de Aula Invertida (PASAI) foi elaborada e aplicada para um bloco de conteúdos envolvendo o ensino da álgebra. A partir disto, a questão que norteou o desenvolvimento da investigação foi: na percepção dos pais, dos alunos, da equipe pedagógica e do professor pesquisador, quais as possibilidades e quais as limitações da utilização da metodologia Sala de Aula Invertida em aulas de matemática para uma turma de $8^{\circ}$ ano?

Deste modo, o principal objetivo foi identificar as possibilidades e limitações do uso da metodologia da Sala de Aula Invertida em aulas de matemática por meio da PASAI. 
Neste artigo, destacamos em especial, a utilização das Tecnologias Digitais da Informação e Comunicação (TDIC) neste processo.

A fim de melhor compreender os fenômenos de estudo propostos na pesquisa a partir das perspectivas dos participantes (alunos, os pais ou responsáveis dos alunos, a coordenação pedagógica e o professor pesquisador), elaborou-se uma pesquisa de campo, do tipo pesquisa-ação (Thiollent, 2011) de natureza qualitativa. Para a produção de informações foram utilizados os recursos: observação e diário de campo do pesquisador (que é também o professor da turma onde a pesquisa foi desenvolvida), questionários pré e pós-aplicação da proposta metodológica aos pais e alunos, gravações de áudio das aulas, registro de atividades dos alunos e relatórios da coordenação a. As informações foram produzidas durante as 40 horas/aulas de matemática do professor, no período de 23 de março de 2017 a 21 de abril de 2017.

Para a análise destas informações, foi escolhido o método de Análise de conteúdo de Bardin (2006), o qual pode ser definido como um conjunto de técnicas utilizadas para descrever e interpretar o conteúdo de todo o tipo de documentos e textos. A autora sugere três fases para esta análise: a pré-análise, a exploração do material e o tratamento dos resultados, inferência e interpretação.

Em vista do exposto, o presente artigo está organizado em nove seções: a primeira consiste nesta introdução, a qual apresenta a problemática, objetivos e metodologia da pesquisa. Nas seções 2, 3 e 4 discutimos sobre aspectos que envolvem as tecnologias digitais no ensino da Matemática, a internet como ferramenta de ensino e sobre a avaliação. Na seção seguinte são apresentados tópicos sobre as metodologias de ensino ativas. A seção 6 apresenta a PASAI. Nas seções 7 e 8 são apresentados, respectivamente, as análises, percepções e os resultados da pesquisa. Finalmente, na última seção tem-se as reflexões e considerações finais.

\section{O uso de Tecnologias Digitais de Informação e Comunicação (TDIC) para o ensino de matemática}

A utilização das chamadas Tecnologias Digitais de Informação e Comunicação (TDIC) tem sido um tema presente em diversos debates, considerando suas potencialidades e limitações no contexto atual de nossas escolas. As tecnologias estão propiciando uma verdadeira revolução na sociedade, e não é possível excluir deste contexto os processos de ensino e de aprendizagem de matemática. 
Neste sentido, Damaceno argumenta que:

O processo de ensino e aprendizagem da matemática vem se tornando uma tarefa difícil para os professores dessa área, os alunos não conseguem assimilar os conceitos e conteúdos ensinados pelo professor e as aulas expositivas não têm sido suficientes para sanar as dúvidas e questionamentos dos mesmos. Torna-se imprescindível para o professor a busca de novas metodologias de ensino como ferramenta para o aprendizado e a educação matemática precisa passar por mudanças estruturais e funcionais frente às novas tecnologias. $(2013$, p. 20).

As Metodologias Ativas, que serão tratadas com mais detalhes adiante, podem trazer ao ambiente escolar novas possibilidades para o ensino e para a aprendizagem da Matemática, tornando as aulas mais dinâmicas e colaborativas e promovendo a personificação da aprendizagem. As tecnologias têm um papel importante no desenvolvimento e aplicabilidade de estratégias diferenciadas de ensino, em todas as áreas de conhecimento.

De acordo com Penteado e Borba,

(...) À medida que a tecnologia informática se desenvolve, nos deparamos com a necessidade de atualização de nossos conhecimentos sobre o conteúdo ao qual ela está sendo integrada. Ao utilizar uma calculadora ou um computador, um professor de matemática pode se deparar com a necessidade de expandir muitas de suas ideias matemáticas e também buscar novas opções de trabalho com os alunos. Além disso, a inserção de TI no ambiente escolar tem sido vista como um potencializador das ideias de se quebrar a hegemonia das disciplinas e impulsionar a interdisciplinaridade. (2003, p. 64).

Segundo Alcântara, ao utilizar as TDIC “o professor tem como auxílio um novo recurso de tornar suas aulas mais estimulantes e diferenciadas" e vai além ao afirmar que

O professor/mediador cria certas facilidades aumentando a autoestima dos alunos, além de permitir novos valores e verificando a dificuldade de aprendizagem readaptando com jogos interativos e de fácil entendimento, ou seja, o professor como mediador tem papel significativo e é dele a missão de buscar alternativas viáveis para fazer desaparecer o desinteresse dos alunos que não querem se envolver e participar dos projetos implantados pela escola. (2012).

\section{Como lembra Costa,}

No Ensino da Matemática, ainda, diversos docentes executam suas práticas pedagógicas, baseando-se num método ultrapassado, do ponto de vista da vertente construtivista, abrindo mão do uso das novas tecnologias educacionais, comprometendo a aprendizagem dos estudantes e, bem como, o seu profissionalismo. (2011, p. 3).

No entanto este cenário, gradativamente vai sendo alterado. Conforme resultados positivos são obtidos nas pesquisas e nas práticas escolares, mais adeptos à inserção de ferramentas tecnológicas auxiliando o desenvolvimento das aulas são incorporados. Em 
especial os educadores matemáticos, têm buscado novos métodos para levar à prática da sala de aula, as ideias-chave de construção e de compreensão dos conceitos. As Metodologias Ativas, Modelagem Matemática, Etnomatemática, História da Matemática, Resolução de Problemas, didática da Matemática, Educação Matemática Crítica, Tecnologias Digitais de Informação e Comunicação; Materiais concretos e jogos no ensino de matemáticos podem ser citados como exemplos destas possibilidades metodológicas.

Referindo-se a Matemática, é importante que o professor desenvolva atividades que explorem sua história, importância e suas aplicações. Diante disso, as TDIC em sua trajetória trazem uma visão inovadora, que tem como característica básica a inter-relação entre prática, pesquisa e formação. Bicudo diz que "faz-se necessário o desenvolvimento de momentos que integrem a Matemática e as TICs, de maneira a favorecer a construção de conhecimentos matemáticos, colaborando na concepção de um espaço de investigação e relevância à aprendizagem" (1999, n.p.).

O contato pelas redes sociais digitais entre os docentes e discentes, na disciplina de Matemática se dá não só pela ânsia de o aluno ampliar suas redes de contato, mas, também, para obter ajuda relativa às tarefas escolares e para sanar dúvidas relacionadas aos conteúdos estudados. Os sites de redes sociais, muitas vezes tem o poder de instigar os alunos e os conduzir a obter, por si mesmos, a solução dos problemas.

Como destaque dos últimos anos entre as TDIC, tem-se as redes sociais digitais, que utilizam a internet. As mais utilizadas no Brasil atualmente são Facebook, Youtube, WhatsApp, Facebook Messenger, Instagram, Twitter, LinkedIn, Pinterest, entre outros (Imme, 2020). Faz-se referência também aos métodos de avaliação, como questionários ou formulários on-line.

As TDIC possibilitam o desenvolvimento de um aluno ativo no processo de ensino e aprendizagem, transformador do meio em que vive, pois a tecnologia motiva o aprendizado, levando muitas vezes o aluno a aplicar e praticar o que aprendeu, e o professor a analisar, avaliar e inteirar-se de mais uma metodologia para o ensino.

É possível concordar com Damaceno quando diz que:

Com as TICs é possível criar ambientes onde os usuários, alunos e professores conectados, apresentam-se de forma virtual gerando novas interfaces de aprendizagem, de modo que todos possam contribuir, compartilhar e interagir na construção do conhecimento de maneira mais rápida e dinâmica, colaborando para um desenvolvimento educacional e social mais acentuado. As TIC proporcionam à educação ambiente de aprendizagem, mais adequados à nova sociedade que emerge. Como a escola é muito 
mais que o espaço físico, constituindo-se essencialmente pela sociedade ao qual está inserida, ela passa a ter os mesmos anseios que os agentes envolvidos nessa sociedade. Com isso, as instituições de ensino devem promover a inclusão digital no ambiente escolar. É preciso rever o processo de aprendizagem do mundo atual sem dificultar a inserção das novas tecnologias na escola. (2013, p. 23).

Portanto, torna-se "inovadora" a ideia de utilizar a internet (vídeos, redes sociais, jogos, etc) para o ensino de matemática em classe e extraclasse, onde o aluno poderá, por exemplo, dar continuidade do aprendizado que é dado em sala de aula.

Na PASAI procuramos contemplar as TDIC no ensino da Matemática, em todas as etapas de implantação, possibilitando o uso de diferentes meios tecnológicos e permitindo o acesso a diferentes recursos digitais. O propósito principal foi favorecer uma aprendizagem ativa e colaborativa, onde cada aluno consiga aprender os conceitos matemáticos de forma dinâmica, significativa e que possa compartilhar com os colegas essas experiências.

\section{Sobre a internet como ferramenta pedagógica}

Há pouco mais de uma década, Vieira disse:

A Internet [...] ainda está numa fase muito embrionária, mas vai explodir. Em 10 anos ela será mais famosa do que a televisão hoje, porque ela, de alguma forma, vai-se ligar com todas as outras mídias, porque ela não vai ser acessada somente por um computador, que é caro, mas também por outras tecnologias, agora pelo celular, vai estar no carro, vai estar em nossa casa, em qualquer eletrodoméstico, teremos um acesso por mil formas que nós hoje nem imaginamos. Será uma mídia extremamente popular nesses próximos anos. Ela vai se tornar a maior mídia em massa. (2006, p. 21).

Possivelmente muitos duvidaram dessas premissas, ou no mínimo imaginaram uma perspectiva exagerada. No entanto, sabemos hoje que a internet se popularizou e atingiu praticamente todas as áreas de nossas vidas, inclusive e fortemente têm surgido com aliada aos processos de ensino e aprendizagem.

Não é novidade que é possível hoje, por exemplo, concluir um curso de atualização, uma graduação, uma pós-graduação ou algo do gênero, por meio da internet. Facilmente podemos pesquisar e aprender sobre diversas coisas, ver videoaulas, acompanhar eventos, ler notícias imediatamente atualizadas, tudo on-line. Ou seja, podemos obter conhecimento, ensinar e/ou aprender sobre diversos temas, assuntos ou conteúdos, por meio desta rede mundial.

Atualmente, vemos uma "geração digital", onde crianças já nascem no meio tecnológico e, querendo ou não, são atraídas e tornam-se dependentes das novidades que 
há poucas décadas nem existiam. Os recursos tecnológicos estão cada vez mais presentes nas casas e nas escolas, em especial a internet. Esta pode ser vista como um recurso dinâmico e interativo, que proporciona novas maneiras de ensinar e aprender, oferecendo uma variedade de benefícios no processo de aprendizagem, facilitando o acesso a recursos didáticos e melhorando a interação entre professores e alunos.

As modernas tecnologias proporcionam ferramentas inovadoras para o intercâmbio de informações no âmbito global e em tempo real. O compartilhamento do conhecimento tem sido a base da inovação e da produção de novos saberes (Moran, 1997; Machado, 2005). A internet, que pode ser definida como uma rede de comunicação mundial que interliga milhões de computadores ao redor do mundo, intercomunicando milhões de dispositivos, tem sido uma das grandes responsáveis por essa difusão, promovendo uma troca interdisciplinar de saberes e estando aberta em todos os aspectos, sendo utilizada como complemento na formação obtida em sala de aula, revolucionando a socialização e a especialização do conhecimento (Velloso, 2004; Machado, 2005; Da Costa \& Bianchini, 2008).

Devido a tantas mudanças no meio tecnológico e com o crescente uso da internet por milhares de pessoas, aparecem novos desafios para a educação e devido a isso, são exigidas novas formas de ensinar e aprender. Esses confrontos não se definem somente na utilização de tecnologias em si. A questão é saber como integrar as tecnologias em projetos pedagógicos, participativos e inovadores.

Há alguns anos, o acesso a computadores ou aparelhos eletrônicos que possibilitassem o acesso à internet era, de certa forma, restrito a pesquisadores, grandes instituições e universidades, governos, ou a minoria da população devido ao alto custo que era exigido para tal comodidade. Atualmente, uma das vantagens tecnológicas que o aluno e o professor podem ter em relação à internet, é que a mesma pode ser acessada em inúmeros lugares, a qualquer momento, através de tantos dispositivos eletrônicos, sejam eles computadores, notebooks, tablets, smartphones, relógios, etc. Dessa forma, é aceitável afirmar que a internet pode manter interligados professor, conhecimento e aluno para além das paredes de uma sala de aula. Nessa perspectiva, pode-se dizer que existirá uma interatividade entre aluno e professor, gerando assim um aprendizado colaborativo, como afirma Casagrande:

Uma característica importante quanto ao uso da internet, é que a mesma possibilita o aprendizado colaborativo, o que significa que tanto alunos como professores são 
participantes ativos no processo de aprendizagem. Desta maneira, o objetivo da educação não é apenas ensinar fatos, mas principalmente, ensinar os alunos a pensar, a raciocinar, bem como, a trocar ideias e informações com seus colegas. (2008, p. 5).

O professor não precisa ser especialista no uso da internet, mas é preciso conhecer as possibilidades dessa ferramenta no processo de ensino e aprendizagem, saber usá-la com o intuito de desenvolver aulas mais prazerosas e dinâmicas. "Muitas vezes os alunos se sentem mais seguros no uso das tecnologias, quando percebem que o professor se utiliza de tais recursos de maneira útil e significativa" (Souza, 2013, p. 20).

Como tudo que é novidade em relação às metodologias de ensino, temos fatores positivos e algumas dificuldades em relação ao uso de tecnologias para o ensino, nesse caso a internet. Uma das necessidades é que exista de fato, concretamente, a possibilidade do acesso à internet, tanto para o professor quanto para o aluno. A grande maioria das escolas já dispõe de internet de qualidade e disponibilizam aos professores e alunos no ambiente escolar. Mas em outros espaços, como a residência, este acesso muitas vezes não existe, o que pode dificultar o desenvolvimento de atividades extraclasse. Por esta razão, o acesso livre de internet para todos, é uma necessidade cada vez mais emergente em nossa sociedade, no entanto depende de políticas públicas nacionais, estaduais e/ou municipais, ou seja, uma variável que não temos controle.

Uma outra dificuldade diz respeito aos professores que utilizam as novas tecnologias sem refletir muitas vezes sobre o seu papel pedagógico e didático, o qual deveria estar direcionado para uma prática construtiva do conhecimento. Tal situação não é objeto desta discussão, mas têm sido tratadas em outras pesquisas que apontam a formação continuada e mudanças na formação inicial de professores como potenciais soluções.

Além disso, outro problema que pode surgir diz respeito às inúmeras possibilidades de conteúdo oferecidas pela internet que encantam os alunos e podem tirar o foco principal do ensino, geralmente a interpretação das informações. Ao utilizarem a internet, os alunos podem ficar dispersos navegando pelos sites, abrindo muitas páginas, confundindo qualidade com quantidade. Existe um deslumbramento com as imagens e sons encontrados na internet, levando muitas vezes os alunos a não considerarem o conteúdo, consumindo a informação de modo rápido e superficial, sem internalizar e refletir sobre ele. Nesses casos, é indispensável a orientação do professor, e dos pais e/ou responsáveis, quanto ao uso correto e adequado da mesma, aconselhando-os para que possam dominar a internet, e não se deixar dominar por ela. 
Como uma das vantagens já citadas, o uso da internet na educação revela-se como um meio de relevantes possibilidades pedagógicas, não se limitando apenas a uma disciplina ou a uma única forma de ensino, permitindo assim a interdisciplinaridade e estimulando o processo de ensino e aprendizagem em todos os níveis de ensino, a começar pelo fundamental. O acesso à internet permite o contato com informações de todo o tipo e dessa forma pode ampliar as possibilidades educativas, uma vez que atividades, tarefas, histórias, pesquisas, vídeos dentre outros estão ao alcance de um clique. Varela e Valenzuela (2020) em pesquisa sobre a utilização das tecnologias em cursos de formação inicial, concluem que de um modo geral os alunos demonstraram um interesse maior nas aulas quando manipularam recursos tecnológicos, inclusive nas aulas de matemática, onde exploravam softwares e procuravam aprender por tentativa e erro.

A internet pode ser utilizada como uma ferramenta didática de ensino que proporciona aos alunos novas descobertas, rompendo com velhos hábitos e paradigmas da educação e propiciando práticas pedagógicas inovadoras.

Para os professores atentos às inovações, a internet torna-se de grande valia, pois são agentes do sucesso dessa aliada do ensino na educação. Por esta razão as concepções, percepções e crenças do professor sobre o uso da internet no ensino, são fundamentais para o bom uso desta ferramenta no ensino. Neste sentido, Varela e Valenzuela (2020) apontam que as habilidades digitais dos professores influenciam significativamente a frequência de uso da internet no espaço escolar e a segurança no desempenho dos mesmos.

\section{Sobre a avaliação e as TDIC}

Geralmente quando se fala em avaliação muitos alunos ficam com medo e apreensivos quanto ao que vai ser cobrado na prova, pois esse é um momento muito tenso e de muita pressão para os alunos.

No entanto, a avaliação deve ser encarada como um processo natural que acontece para que o professor tenha uma noção dos conteúdos assimilados pelos alunos, bem como para saber se as metodologias de ensino adotadas por ele, estão surtindo efeito na aprendizagem dos alunos. Há muito tempo, avaliar significava apenas aplicar provas, dar uma nota e classificar os alunos em aprovados e reprovados. Ainda hoje existem alguns professores que acreditam que avaliar consiste somente nesse processo. Contudo, essa visão aos poucos está sendo modificada. 
Segundo Nóvoa e Estrela a avaliação é atualmente

Uma área de enorme complexidade técnica e científica, seja pela dimensão formativa, com o objetivo de acompanhar o desenvolvimento do aluno e orientá-lo no processo, ou pela dimensão somativa; da regulação, compreendendo por esta dimensão como o necessário à correção dos desvios significativos, do monitoramento das atividades previstas no planejamento, e da certificação, a avaliação pode ser considerada como um processo decisório. (1993, n.p.).

\section{Como Perez afirma,}

Muitas técnicas de avaliação podem ser utilizadas pelos professores de matemática, a saber: provas com questões de resposta aberta, tarefas de resposta curta, itens de múltipla escolha, tarefas de desenvolvimento, observação, pesquisa e redações matemáticas, jogos, WebQuests e portfólios, entre outros. [...] Acredita-se que aspectos como interação, feedback, diálogo e envolvimento ativo dos alunos no processo de ensino e aprendizagem e na avaliação, que inclui o avaliar a si próprio e aos outros, contribuem para promover o domínio de procedimentos e a compreensão conceitual através da resolução de problemas, do raciocínio e da argumentação. (2015, p. 27).

Sabe-se que existem inúmeras formas de avaliar um aluno, de acordo com o ambiente escolar, em relação ao comportamento, utilizando provas discursivas e de múltipla escolha, trabalhos escolares, tarefas de casa, comprometimento escolar, participação nas aulas e nos eventos escolares, etc. Todos esses meios são utilizáveis na constituição de uma nota.

Como destacado por Fernandes, ainda em muitas situações,

Prevalece uma avaliação pouco integrada ao ensino e a aprendizagem, mais orientada para atribuição de classificações do que para análise cuidadosa do que os alunos sabem, e são capazes de fazer, ou para compreender as suas eventuais dificuldades, ajudando-os a superá-las. (2007, p. 587).

Mas como seria possível relacionar a avaliação matemática com as Tecnologias Digitais de Informação e Comunicação? Como exemplo, atualmente, em cursos de Ensino a Distância $(\mathrm{EaD})$ já é absolutamente normal a existência de provas, trabalhos, webquests, fóruns, entre outros métodos de avaliação, todos on-line, realizados através da internet.

Pode-se então refletir que sendo uma pesquisa, um trabalho, uma lista de exercícios, o desempenho em um jogo ou em um software matemático, em sala ou extraclasse, todos podem ser utilizados como forma de avaliação do aluno. Seja essa análise por nota ou simplesmente pelo desempenho do discente, o professor deve lembrar que a avaliação vai muito além, podendo inclusive avaliar a si mesmo.

A internet combina interatividade com fotos, áudio, vídeo e texto impresso; utiliza hiperlinks para reforçar conhecimentos ou apresentar explicações; permite que sejam 
efetuadas avaliações on-line. Enfim, esse instrumento representa um novo conceito em tecnologia: a livraria em sua mesa de trabalho, o dicionário em seus dedos, o som em seus ouvidos. "Não há nada que possamos ver ou ouvir que não possa ser disponibilizado por ela" (Colossi et. al., 2001).

Entende-se, dessa maneira, que além de possível, seja também necessário incorporar os recursos disponíveis a partir do uso da internet dentro e fora da sala de aula, seja para ensino ou avaliação, de maneira que as possibilidades de acesso à informação se multipliquem e que interações entre professor e aluno aumentem, entre outros aspectos importantes.

O importante é entender que avaliar não consiste somente em fazer provas e dar nota, avaliar é um processo pedagógico contínuo, que ocorre dia após dia, buscando corrigir erros e construir novos conhecimentos.

\section{Sobre as metodologias ativas}

Na passagem do século XX para XXI, já havia grande preocupação com os métodos de ensino até então utilizados, como cita Gadotti, "um novo mundo globalizado e informatizado se apresenta e com ele muitas áreas como a educação tem de rever conceitos, métodos e quebrar paradigmas para suprir as demandas do ensino" (2000, p. 8).

É sabido que, atualmente, a prática de ensino tradicional utilizada por muitos professores não colabora para que os alunos possuam maior interesse no conhecimento em si transmitido. "Baseadas na memorização, as aulas são geralmente cansativas e desestimulantes trazendo como consequência a perda de interesse dos alunos pelo conteúdo e quase que inevitavelmente a atenção desviada para outros assuntos" (Francisco, s. f.).

Na missão de tornar a carreira do professor mais atrativa e formá-lo para lidar com um aluno cuja vida é mediada pela tecnologia, universidades internacionais também se veem diante do objetivo de mudar suas metodologias adotadas nas faculdades de educação. É o caso da Relay Graduate School of Education, dos Estados Unidos. Segundo Oliveira

Dentre outras inovações trazidas pela Relay, está a criação de uma biblioteca digital, com vídeos gravados em escolas reais, que pode ser consultada de acordo com a necessidade. Eles gravaram por centenas de horas, separaram e classificaram os vídeos de acordo com seu currículo. Quando os alunos precisavam saber mais sobre o que estavam falando, não ficavam só na teoria, eles poderiam ver em ação. Esse formato é especialmente útil pelo formato híbrido adotado para as aulas: $40 \%$ do conteúdo é apresentado online e o 
restante, presencial. Após assistir a uma aula introdutória em casa, o aluno pratica em sala de aula e recebe feedback de professores. (2016).

Mas será que as propostas e objetivos das novas metodologias de ensino têm ligações ou semelhanças com as do passado? Certamente.

Em 1932, Anísio Teixeira, Lourenço Filho e Fernando de Azevedo foram líderes e signatários de um manifesto - o "Pioneiros da Educação", criticado pela ingenuidade e aclamado pela inovação - que propunha mudanças na educação brasileira. Essas propostas, no que tange ao viés pedagógico do documento, possuíam vinculações com a Escola Nova - movimento do final do século 19 adentrando o século 20 - que, entre outros itens, se baseava no aluno como centro da aprendizagem; em trabalhos manuais; experimentações e em um aprendizado mais significativo (Sanches, 2015).

Seguindo nessa linha, uma percepção das correntes pedagógicas do final do século 19 e do século 20 revela muitas semelhanças em relação a algumas propostas pedagógicas inovadoras da atualidade. Ainda segundo Sanches,

Para Vygotsky, por exemplo, o sócio interacionismo era um caminho a ser traçado na educação, ou seja, o aprender com o outro era fundamental, pois ninguém aprende sozinho. Já Paulo Freire se notabilizou pela aprendizagem significativa, trabalhando com o que o indivíduo já sabia e vivia em seu cotidiano, ou seja, do que experimentou em sua realidade, não sendo uma folha em branco a ser preenchida. Ausubel, psicólogo estadunidense, também desenvolveu teoria baseada na aprendizagem significativa, partindo do que o aluno já sabia. (2015).

Torna-se interessante, então, nessa perspectiva, investigar e analisar o que está se propondo, hoje, para a melhoria da educação em relação à estas metodologias. Quais são as principais propostas em pauta? Um aprendizado baseado no aluno; o "aprender" mais do que "o ensinar"; uma aprendizagem mais colaborativa; uma abordagem mais significativa que tenha mais contato e ligação com o mundo real; mais experimentações em projetos e outros mais.

Metodologias como Aprendizagem Baseada em Projetos (ABP, ou, PBL em inglês), Ensino Híbrido ou Design Thinking, entre outras, têm como objetivo desenvolver nos alunos algumas das propostas citadas no parágrafo anterior e tidas como fundamentais para o século 21 .

Então, atualmente, o que se desenha é uma retomada de pressupostos já estudados e bem definidos no passado, com as tecnologias da informação e comunicação atuando como 
mediadoras e facilitadoras do processo, além das adequações de alguns itens ao nosso momento - pelo menos em parte dos casos.

Para Sanches,

Esses são pontos importantes a serem considerados: o momento e a adequação. Assim como à época do manifesto dos "Pioneiros da Educação", necessitamos de um sistema de ensino e de metodologias que preparem o aluno para a sociedade contemporânea. A sociedade da informação e que vive em rede. E também prepare para um mercado de trabalho em constante transformação, que precisa de pessoas colaborativas, proativas, criativas, com capacidade de resolver problemas inéditos e sem um "manual de instrução". (2015).

Ou seja, embora possa haver alguma "novidade" na aplicação das novas metodologias de ensino, suas propostas e objetivos são semelhantes ao que já se discutiu e se propôs no passado.

Uma leitura atenta dos três trechos a seguir, extraídos do Manifesto dos Pioneiros da Educação Nova (Azevedo, 2010) dará uma boa noção dessa semelhança:

[...] O que distingue da escola tradicional a escola nova, não é, de fato, a predominância dos trabalhos de base manual e corporal, mas a presença, em todas as suas atividades, do fator psicobiológico do interesse, que é a primeira condição de uma atividade espontânea e o estímulo constante ao educando (criança, adolescente ou jovem) a buscar todos os recursos ao seu alcance, graças à força de atração das necessidades profundamente sentidas. (p. 49).

[...] a escola deve utilizar, em seu proveito, com a maior amplitude possível, todos os recursos formidáveis, como a imprensa, o disco, o cinema e o rádio (p. 62).

[...] Mas, o exame, num longo olhar para o passado, da evolução da educação através das diferentes civilizações, nos ensina que o "conteúdo real desse ideal" variou sempre de acordo com a estrutura e as tendências sociais da época, extraindo a sua vitalidade, como a sua força inspiradora, da própria natureza da realidade social. (p. 39).

Nesses trechos, pode-se perceber ao menos três itens comuns ao que se propõe hoje: (1) interesse do aluno pelas tarefas que vai realizar; (2) utilização dos recursos tecnológicos disponíveis; e (3) a ligação da educação com a sociedade do seu tempo;

No Brasil, algumas escolas públicas e particulares estão inovando nessa linha. Mas essas iniciativas ainda são muito incipientes, pontuais e, em alguns casos, inconstantes (Sanches, 2015).

Estamos em um momento de transição e há um claro descompasso entre a escola, o mundo corporativo e a sociedade. $\mathrm{O}$ que tem travado muito essa evolução, entre outros fatores, é o paradigma baseado em práticas de ensino tradicionais. 
Atualmente, existem muitas metodologias sobre como ensinar para essa geração conectada. Porém, alguns termos não estão claros para todos os professores, que acabam "deixando de lado" sua existência por não saber o que significam e não conseguirem usar esta ou aquela metodologia. Mas, se analisarmos com atenção, tudo está conectado. É como se estivéssemos diante de uma única metodologia com várias vertentes, que se complementam.

Por exemplo, algo que está em alta nas discussões a respeito das metodologias é a Blended -Learning. Também conhecido como B-Learning ou Ensino Híbrido (em português), nada mais é que misturar atividades presenciais com atividades a distância. Provavelmente, muitos educadores e instituições já deram os primeiros passos nessa direção e nem percebiam que estavam fazendo algo tão inovador. Para Moretto (2015), "essa metodologia permite ao professor ampliar sua sala de aula, oportunizando uma aprendizagem colaborativa, tanto presencial quanto virtual. Não se trata de abrir mão dos espaços, mas unificá-los, deixando a sala de aula mais ampla".

Dentre as estratégias metodológicas, tem-se a Sala de Aula Invertida, tema tratado nesta pesquisa. Trata-se de inverter a "lógica" da sala de aula, permitindo que os alunos tenham contato com o conteúdo antes da aula presencial, em casa. Ou seja, a aula começa com a tarefa de casa. Pode ser através de um vídeo, um game educativo ou outros recursos virtuais. Desta forma, o aluno já adquire um conhecimento prévio sobre o conteúdo/assunto e utiliza a sala de aula física para tirar as dúvidas e fixar o que aprendeu, tendo suporte do professor, que passa a ser um mediador do conhecimento adquirido, e dos colegas. Segundo Moretto, "é uma metodologia que motiva atividades colaborativas, em grupo, a criação de projetos e promove o envolvimento dos alunos" (2015). De acordo com Moran, "a melhor forma de aprender é combinar "atividades, desafios e informação contextualizada" (2015, p.17).

Contudo, antes de começar a colocar em prática tais metodologias citadas anteriormente, o educador precisa estar preparado. E se tratando do uso de TDIC, o professor necessitará de um upgrade metodológico, onde devem explorar ambientes online, plataformas de aprendizagem, repositórios de recursos educativos digitais, saber o que é e como utilizar as redes sociais, saber pesquisar na internet, organizar arquivos on-line, entre outros aprendizados. Isso pode ser feito, por exemplo, na formação inicial e/ou continuada dos professores. 


\section{A proposta metodológica}

$\mathrm{Na}$ aplicação da metodologia Sala de Aula Invertida (SAI), a inversão proposta aparece, principalmente, no deslocamento do protagonismo da sala de aula: se no modelo tradicional de ensino, o professor atua como detentor do saber em um palco, para quem todas as atenções devem estar voltadas, na SAI ele é o coadjuvante que trabalha ao lado dos alunos, como orientador da aprendizagem. De acordo com Bergmann e Sams (2016, p. 6), o modelo Flipped Classroom (como é chamada a metodologia, em inglês) "pode atender às necessidades dos alunos pois permite que seus professores personalizem a sua educação". Tanto a metodologia de ensino quanto a de aprendizagem passam por uma ressignificação, uma vez que os modelos tradicionais de sala de aula também são invertidos: a "tarefa de casa" vai para dentro da sala de aula, enquanto as aulas teóricas ficam do lado de fora, on-line (através de redes sociais, blogs, vídeos, etc). Tal modelo se apropria de recursos virtuais e digitais de instrução e interação para a disseminação do conteúdo didático previamente às aulas, tendo como objetivo aumentar, dentro de sala de aula, o tempo de interação entre professor e aluno.

De acordo com Bergmann e Sams, neste método de ensino,

O tempo é reestruturado, de modo que os primeiros minutos de aula são dedicados a responder questões dos alunos sobre o conteúdo entregue previamente, o que permite esclarecer equívocos antes de os conteúdos serem praticados e aplicados incorretamente. O tempo restante é usado para atividades práticas mais extensas e/ou resolução de problemas dirigidos. (2016, p. 12).

Como princípio desta metodologia ativa, a Sala de Aula Invertida tem como objetivo "prover aulas menos expositivas, mais produtivas e participativas, capazes de engajar os alunos no conteúdo e melhor utilizar o tempo e conhecimento do professor" (Paiva, 2016).

Diante disso, a Proposta de Aplicação da Sala de Aula Invertida (PASAI) surgiu da "necessidade do professor pesquisador em tornar as suas aulas mais dinâmicas, produtivas e participativas, nas quais o aluno pudesse ser protagonista do ensino dentro da sala de aula, e o professor um orientador e/ou mediador do conhecimento" (Almeida, 2017, p. 46). Neste estudo, adaptamos a metodologia Sala de Aula Invertida proposta por Bergmann e Sams (2016) à realidade do professor pesquisador e à rotina da turma, para o ensino de equações; desigualdades e inequações; equações do $1^{\circ}$ grau com duas incógnitas e sistemas de equações do $1^{\circ}$ grau com duas incógnitas para turmas do $8^{\circ}$ ano do Ensino Fundamental 
II. Por esse motivo, a PASAI foi dividida em 5 etapas: Motivação; Material online; Resolução e apresentação de tarefas; Resolução de desafios e Diversificação de tarefas.

A aplicação desta proposta teve como público alvo estudantes com idades entre 12 e 14 anos, de duas turmas (15 e 16 alunos, respectivamente) de $8^{\circ}$ ano do Ensino Fundamental II, de uma escola particular localizada no sudoeste do Paraná. O turno de frequência regular destas turmas é matutino, sendo que as aulas de Matemática somam 5 (cinco) horas/aulas de 50 minutos cada, durante a semana, onde cada turma tem 1 aula por dia desta disciplina. Para efetivação da pesquisa, foram utilizadas as aulas regulares de Matemática, num processo contínuo de cinco horas/aulas semanais durante 4 semanas (cerca de 40 horas/aula). Em cada uma destas quatro semanas foram desenvolvidas as 5 etapas da PASAI para os conteúdos matemáticos já citados.

Na etapa "Motivação", os estudantes foram instigados a conhecer o conteúdo que viria a ser estudado de uma forma lúdica, porém introdutória e básica, que os atraísse a se interessar pelas futuras aulas que viriam. Salientamos que esta etapa, mesmo estando intimamente ligada à próxima, já traz um pouco da essência da Sala de Aula Invertida, que é o aluno ser motivado a aprender antes de efetivamente "ser ensinado" a ele algum conteúdo. Como exemplo, usado em nossa pesquisa, realizamos perguntas questionadoras e aplicamos jogos e atividades lúdicas em todas as aulas desta etapa, obviamente estes eram focados no conteúdo que seria trabalhado.

A etapa "Material online" foi subdivida em três momentos: o primeiro realizado ainda extraclasse com o uso de TDIC (videoaulas selecionadas e enviadas via Whatsapp no interstício da etapa 1 e 2, deveriam ser assistidas pelos alunos fora do ambiente escolar, para que tivessem o contato inicial com os conteúdos que seriam discutidos efetivamente pelo professor); o segundo momento, realizado em sala de aula, com a discussão e formalização do conteúdo por meio da intervenção do professor; e o terceiro, o desenvolvimento de exercícios e problemas em grupos, de forma colaborativa. Nesta etapa, efetivamente, a metodologia da Sala de Aula Invertida coloca-se em prática: no momento em que o aluno assistia as videoaulas e estudava sozinho, procurando detalhes e percebendo dúvidas sobre o conteúdo; e no momento em sala de aula, na qual o professor explorava os conteúdos já visualizados pelos alunos nos vídeos, resolvendo exercícios, explicando detalhes e sanando possíveis dúvidas. 
Quanto à etapa "Resolução e apresentação de tarefas", os grupos de alunos foram designados a apresentarem seus exercícios e resoluções, distribuídos a eles na etapa anterior. Isso possibilitou maior liberdade e autonomia dos alunos para a discussão dos exercícios, pois respondiam dúvidas dos demais grupos, ou também, como por muitas vezes, surgiam caminhos diferentes para a resolução de um problema.

Na etapa da "Resolução de desafios", os mesmos grupos de alunos apresentavam as resoluções dos desafios que lhes era proposto na aula da etapa anterior. Assim como as videoaulas, estes eram enviados via grupo no Whatsapp. Diferente das atividades e tarefas dadas anteriormente, esses desafios exigiam um raciocínio mais detalhado dos objetivos que deveriam ser alcançados em relação ao conteúdo estudado naquela semana. Inclusive, alguns alunos preferiam gravar suas resoluções utilizando seus smartphones e enviavam a resolução através de vídeos - que eles podiam editar, fazer cortes e junção de cenas, etc.

Para finalizar, a etapa "Diversificação de tarefas" tinha como objetivo a proposição de tarefas variadas, que pudessem explorar aspectos dos conteúdos ainda não destacados, como jogos, modelagem e história da matemática. Esta atividade tornou a proposta ainda mais atrativa aos alunos, já que iniciavam e encerravam a semana com diferentes tarefas lúdicas envolvendo o conteúdo trabalhado. Outro detalhe importante desta fase é que os alunos recebiam, em horário extraclasse, e também através do grupo do Whatsapp, o link para realização dos trabalhos on-line. Estes continham exercícios (duas ou três atividades, com alternativas) feitos através do "Google Formulários", e que faziam parte do processo avaliativo de cada aluno. Esses trabalhos puderam ser realizados por eles com consulta aos seus materiais e exibiam, após sua finalização, a nota obtida. O prazo para sua conclusão era o início da semana seguinte, onde todas as etapas iniciavam novamente. Vale ressaltar que alguns vídeos foram selecionados da plataforma de compartilhamento de vídeos Youtube (como por exemplo, uma videoaula sobre Equações do $1^{\circ} \operatorname{grau}^{1}$ ), outros, como os vídeo-desafios como, por exemplo, sobre Sistemas de Equações do $1^{\circ}$ grau com duas incógnitas $^{2}$, foram elaborados pelo professor pesquisador.

\footnotetext{
${ }^{1}$ Disponível em https://www.youtube.com/watch?v=Ylvb03POwGE

${ }^{2}$ Disponível em https://youtu.be/4PWp3a8-OhQ
} 


\section{Análise dos dados e percepções}

Conforme já informado, o método de análise dos dados que adotamos foi a Análise de Conteúdo, proposto por Bardin (2006). Produzimos a organização da análise em torno dos três polos sugeridos pela autora: pré-análise; exploração do material; tratamento dos resultados, inferência e interpretação.

Na primeira etapa, a pré-análise, selecionamos os materiais que compõe o conjunto de dados a serem analisados. Assim, o diário de campo do professor; as gravações de áudio das aulas; os questionários dos alunos (pré e pós-aplicação da PASAI); os questionários dos pais (pré e pós-aplicação da PASAI) e relatórios da equipe pedagógica constituíram o material a ser analisado. A partir da seleção do material, procedemos o passo da unitarização. As unidades de análise constituem-se de excertos das respostas descritivas dos questionários dos alunos e dos pais; recortes das falas dos alunos durante as gravações de áudio das aulas, relatórios produzidos pela equipe pedagógica e comentários citados no diário de campo do pesquisador.

Seguindo os pressupostos de Bardin (2006), definimos as categorias a priori, ou seja, pelo procedimento denominado pela autora de caixas. Neste caso, foram previamente determinadas a partir da teoria e da proposta metodológica elaborada (PASAI), onde as subcategorias seriam delimitadas a partir dos objetivos e da questão de pesquisa. Como critério de análise destas subcategorias, focamos nas percepções dos envolvidos no processo. Em decorrência desses procedimentos, foram estabelecidas as seguintes categorias: Motivação; Material online; Resolução e apresentação de tarefas; Resolução de desafios; Diversificação das tarefas, que são exatamente as 5 etapas que elaboramos na PASAI.

Os excertos das respostas descritivas dos questionários dos alunos e dos pais, assim como o diário de campo do professor e suas percepções, serviram como unidades de análise para todas as categorias. Os relatórios produzidos pela equipe pedagógica se encaixaram como unidades de análise para as categorias: motivação; material online; resolução e apresentação de tarefas e diversificação das tarefas.

Todas as etapas de análise (preparação das informações; transformação do conteúdo em unidades, categorização, descrição e interpretação) se complementaram e interagiram, a ponto de que nesta investigação após a pré-análise, as etapas praticamente não se distinguiram. 
Na figura a seguir são apresentadas as categorias de análise que deram suporte à busca de respostas para a questão investigativa:

Quadro 1: Categorias de análise

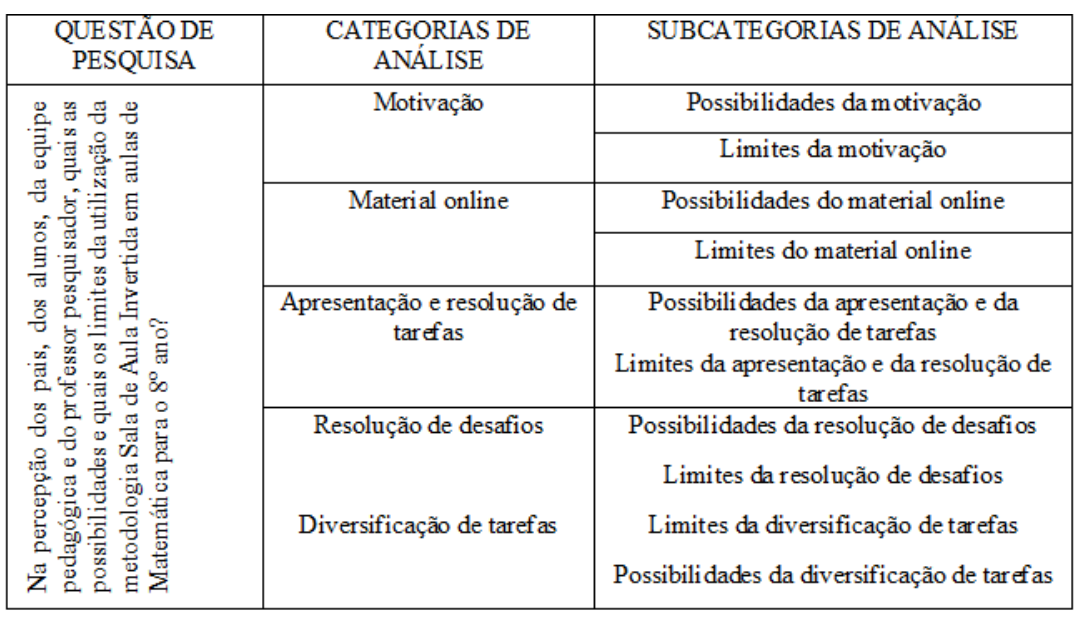

Fonte: Almeida (2017)

Para a discussão e análise das informações, foi necessária a codificação dos dados. Desse modo, todos os dados coletados por meio dos diferentes instrumentos de coleta utilizados na pesquisa foram codificados do seguinte modo:

- PiQ1A: Pergunta $i$ do Questionário 1 dos Alunos, onde $i \in\{1,2,3\}$;

- PiQ2A: Pergunta $i$ do Questionário 2 dos Alunos, onde $i \in\{1,2, \ldots, 8\}$;

- PiQ1P: Pergunta $i$ do Questionário 1 dos Pais, onde $i \in\{1,2,3,4\}$;

- PiQ1P: Pergunta $i$ do Questionário 2 dos Pais, onde $i \in\{1,2,3,4\}$;

- Ai: Aluno(a) $i$, onde $i \in\{1,2, \ldots, 35\}$;

- PMR $i$ : Pai/Mã/Responsável $i$, onde $i \in\{1,2, \ldots, 35\}$;

- PMR: Pai, mãe ou responsável;

- Ci: Coordenadora $i$, onde $i \in\{1,2\}$;

- RCP: Relatório da Coordenação Pedagógica;

A escolha dos recortes (tanto das falas, dos relatos, das respostas dos pais, alunos, professor pesquisador e equipe pedagógica) foi realizada tendo em vista evidenciar os objetivos da pesquisa e traduzir as categorias de análise pré-estabelecidas.

Ao buscar instigar os alunos sobre o conteúdo que seria trabalhado com atividades diferentes do que estavam acostumados como introdução, foi relevante perceber a ótima participação e interesse deles. Algumas das atividades dadas durante as aulas da etapa Motivação despertaram tanto interesse dos alunos que os mesmos pediram para realizá-las em outros momentos, sempre que possível. A fala do(a) aluno(a) A7 durante a gravação de áudio da aula 2 da $3^{\text {a }}$ semana evidencia este fato: "Professor, se sobrar tempo da aula, 
podemos terminar nossa batalha naval? Porque terminamos empatados na 'ultima aula, $e$ aquele jogo nos faz pensar bastante (...)”.

Sendo normalmente a motivação dos alunos um desafio ao professor, era de se esperar que limitações fossem encontradas no desenvolvimento de tarefas específicas para motivar os alunos, detalhes que podem, ou não, ser evitados antes ou durante esta etapa. Entre esses limites, pode ser destacado o tempo da aula. Como nenhuma das aulas eram geminadas, havia 50 minutos entre o diálogo com a turma sobre o que já sabiam sobre o conteúdo e a aplicação de alguma atividade ou jogo que tivesse relação com o mesmo. Porém, como a maioria das atividades eram realizadas em duplas ou em grupo, faltava tempo para que as mesmas fossem finalizadas por completo.

Outra dificuldade encontrada foi a internet, fornecida em tempo integral para todos da escola, que infelizmente não funcionou durante um período de uma das aulas que precisava de acesso para a realização de uma atividade on-line (aula 1 da $1^{\text {a }}$ semana). Claro que, embora tendo sido resolvido o problema técnico após alguns minutos de aula, é aceitável que essa situação aconteça, já que isso independe do professor pesquisador ou dos alunos. Mas de todo o modo, o acesso à internet pode ser considerado como um limite nesta etapa.

Diferentemente da Motivação, o tempo da aula para a discussão sobre a videoaula, a formalização dos conceitos e exemplos com exercícios foi suficiente, e as turmas, em sua maior parte, foram participativas em todos os momentos.

Um dos fatores essenciais para que a etapa Material Online fosse bem sucedida seria os alunos assistirem efetivamente as videoaulas. Durante a aplicação, pode-se observar que a maioria dos alunos cumpriu com essa tarefa, fazendo anotações e esquemas, desta forma facilitando as discussões e formalização do conteúdo. O excerto do(a) aluno(a) A8 demonstra tal fato: 
Figura 1: Possibilidades do Material Online por A8

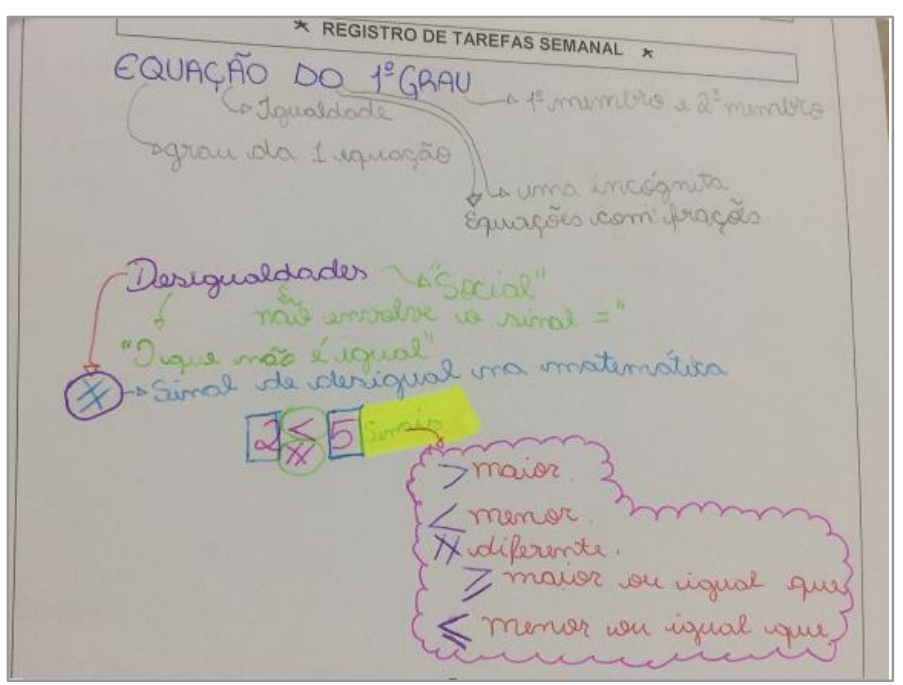

Fonte: Almeida (2017)

Uma das vantagens da utilização das videoaulas é que, antes do professor efetivamente explicar o conteúdo em estudo, o aluno podia ir para a aula com conhecimentos prévios do que aprenderia e seria trabalhado em sala de aula, quem sabe apenas para sanar dúvidas que viessem a surgir.

Outro ponto vantajoso das videoaulas é que os alunos poderiam assistir no momento em que quisessem, podendo pausar ou até visualizá-la quantas vezes desejassem. Jon Bergmann e Aaron Sams falam que a inversão da sala de aula "cria condições para que os alunos pausem e rebobinem o professor, através das videoaulas onde o aluno pode assistir quando e onde quiser, podendo rever quantas vezes for necessário a mesma explicação" (2016, p. 21). Isso é, tecnicamente, impossível de se fazer ao assistir uma aula expositiva e dialogada. Assim, havia a possibilidade de uma maior dedicação para o aprendizado e compreensão dos conteúdos. Em síntese, o aprendizado já era iniciado em casa, e apenas formalizado e intensificado em sala de aula. Parte desses pontos em destaque são citados por A19 e PMR22, ao responderem as perguntas P5Q2A e P1Q2P, respectivamente:

Figura 2: Possibilidades do Material Online por A19

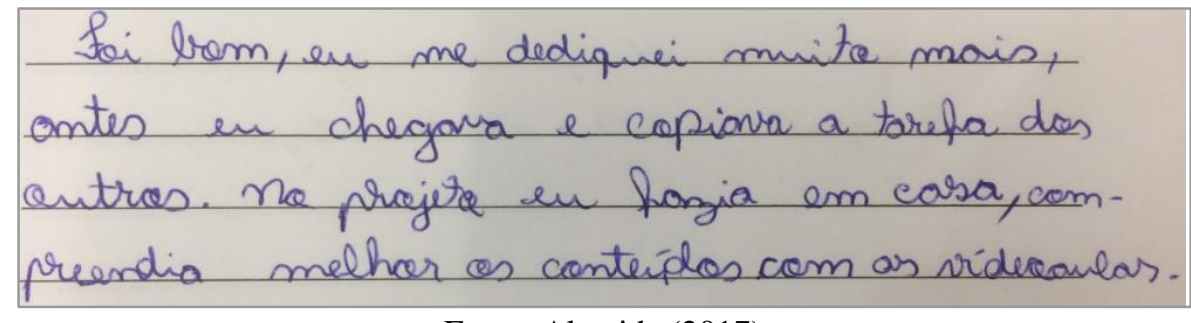

Fonte: Almeida (2017) 
Figura 3: Possibilidades do Material Online por PMR22

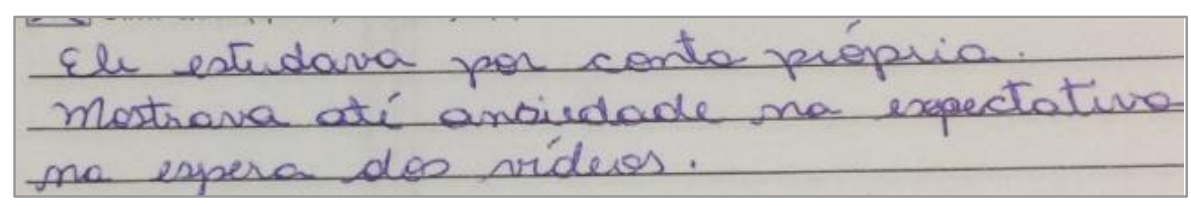

Fonte: Almeida (2017)

Foi interessante perceber que os alunos chegaram a encontrar outras videoaulas, além daquelas que eram indicadas, e compartilhavam entre si no grupo da disciplina no WhatsApp. Assim, como na matemática, dependendo do conteúdo pode existir mais de um caminho para se chegar a um resultado esperado, os alunos assistiam mais do que uma única explicação e acabavam aprendendo outras técnicas ou curiosidades que, talvez, nem o professor pesquisador iria mostrar a eles que existia. Esta possibilidade é comentada por A27 na P7Q2A:

Figura 4: Possibilidades do Material Online por A27

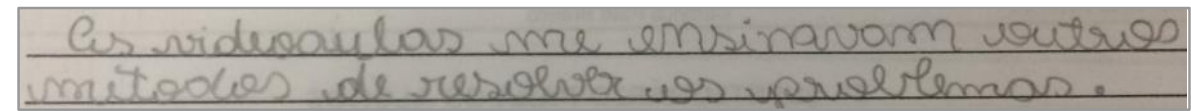

Fonte: Almeida (2017)

Mesmo a maioria dos alunos tendo cumprido com o seu papel de assistir as videoaulas, alguns disseram não ter conseguido assisti-las. Então, como consequência deste fato, não tiravam dúvidas e não tinham grande participação nas discussões sobre as videoaulas naquela aula, ficando assim "perdidos" até que o conteúdo fosse efetivamente formalizado.

Vemos nos recortes que seguem, escritos respectivamente por PMR14 e PMR4, ao responderem a $\mathrm{P} 3 \mathrm{Q} 2 \mathrm{P}$, que alguns responsáveis pelos alunos não tinham a consciência de que, além das videoaulas, também eram usados outros meios (formalização do conteúdo em aula, exemplos, exercícios, atividades lúdicas, entre outros) para que o aluno pudesse compreender o conteúdo:

Figura 5: Limites do Material Online por A27

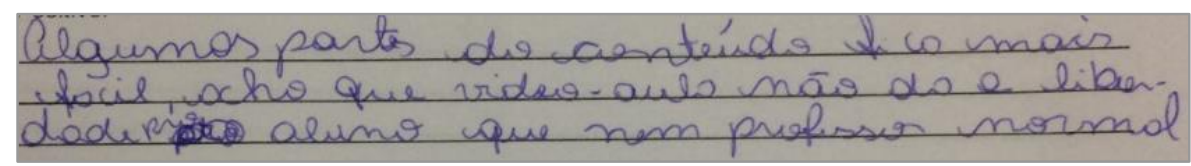

Fonte: Almeida (2017)

Figura 6: Limites do Material Online por PMR4

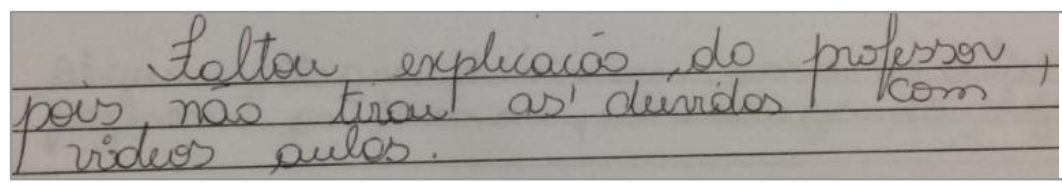

Fonte: Almeida (2017) 
Ao contrário, a função da videoaula era dar liberdade para que o aluno assistisse, pausasse, revisse, onde e no horário que desejasse, antes da aula de formalização, exemplos e resolução de exercícios em aula.

Uma das observações feita no RCP por uma das coordenadoras pedagógicas, C1, foi a seguinte:

Figura 6: Limites do Material Online por C1

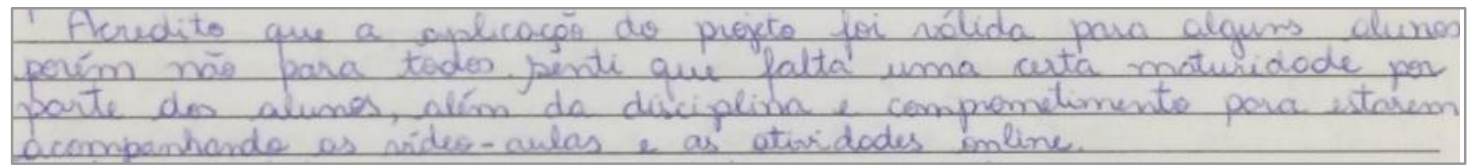

Fonte: Almeida (2017)

Ao analisarmos este recorte, podemos destacar a frase: falta uma certa de maturidade por parte dos alunos. Certamente que não de todos, mas aplicar uma mudança (a metodologia) significativa em sala de aula foi suficiente para percebermos que alguns não tinham um comprometimento e responsabilidade para assistir as videoaulas e cumprir as demais atividades extraclasse. Pensamos que isso tudo deve ter ocorrido pela: idade dos alunos; falta de esclarecimento e auxílio dos pais; falta de maior explicação, por parte do professor, da grande importância dos deveres que os alunos tinham, dentre outros possíveis fatores.

Outro limite encontrado foi que as videoaulas não foram gravadas pelo professor pesquisador, o que era a ideia inicial, devido à falta de tempo e de recursos tecnológicos disponíveis. Logo eram enviadas videoaulas de outros professores, facilmente encontradas no YouTube ou em outros websites. Isso não prejudicou, de forma alguma, o decorrer da pesquisa, mas de certa forma poderia ter facilitado a compreensão dos conteúdos por parte dos alunos, já que estavam acostumados com as formas de explicação do professor e o mesmo poderia dar foco ao que realmente lhes era necessário aprender, de acordo com o material didático deles. Por outro lado, Bergmann e Sams sugerem:

Usar vídeos produzidos por outros professores, em vez de fazer os próprios vídeos, talvez seja a melhor opção para quem está começando a inverter a sala de aula. Talvez você queira fazer a inversão, mas não tenha tempo para produzir os vídeos. [...] Com a explosão do YouTube e outros websites de compartilhamento de vídeos, a quantidade de vídeos disponíveis está crescendo. Muitos deles podem ser usados em uma sala de aula invertida. O importante é encontrar vídeos de qualidade, qualquer que seja a disciplina. (2016, p.32).

Uma das percepções do professor pesquisador sobre esta etapa Resolução $e$ Apresentação de Tarefas, da PASAI, foi que a proposta de trabalho em equipe para a 
resolução e apresentação de tarefas foi muito positiva. A maioria dos grupos conseguiu trabalhar de forma tranquila e com espírito de equipe, ajudando uns aos outros e aos demais grupos. Alguns poucos grupos tiveram colegas que não se envolveram nas tarefas propostas.

Ao alterar a dinâmica da aula formando grupos de pelo menos 4 alunos, em que o professor pôde colocar alunos com facilidade de aprendizado junto de alunos com dificuldades, isso facilitou para que eles pudessem aprender de forma cooperativa, na qual o professor deixa de ser a "fonte de todo o saber", passando a ser apenas o facilitador, tutoreando os alunos durante a resolução e apresentação dos exercícios a eles propostos. Essa vantagem é demonstrada nas respostas da P5Q2A, do(a) aluno(a) A30, que pergunta sobre o que mais lhes chamou a atenção durante a aplicação da proposta:

Figura 8: Possibilidades da Resolução e Apresentação de Tarefas por A30

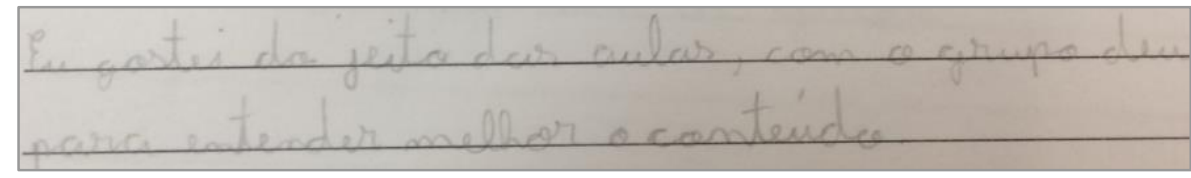

Fonte: Almeida (2017)

Vale ressaltar que todos as tarefas eram resolvidas e, às vezes, durante a apresentação de um grupo, outros alunos comentavam sobre outras formas de resolução do mesmo problema, o que colaborava para a compreensão do tema em estudo. Isso é bem destacado por A7, ao responder suas percepções positivas em seus estudos de Matemática, na P7Q2A:

Figura 9: Possibilidades da Resolução e Apresentação de Tarefas por A7

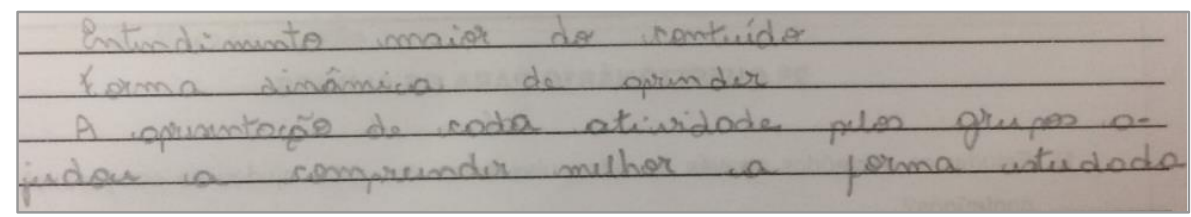

Fonte: Almeida (2017)

Ainda sobre a melhor compreensão do conteúdo, também na visão de PMR14 na P1Q2P:

Figura 10: Possibilidades da Resolução e Apresentação de Tarefas por PMR14

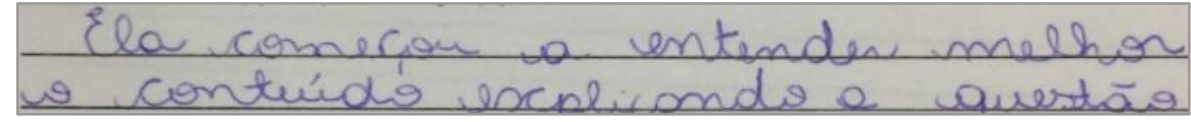

Fonte: Almeida (2017)

Foi interessante perceber que alguns grupos davam o seu melhor para o bem de seus membros, pois, segundo eles, conversavam entre si pela internet, discutiam via 
chamadas de vídeo e até se encontravam fora da escola para desenvolver suas atividades propostas. É o que reforça PMR5 ao responder a P3Q2P:

Figura 11: Possibilidades da Resolução e Apresentação de Tarefas por PMR5

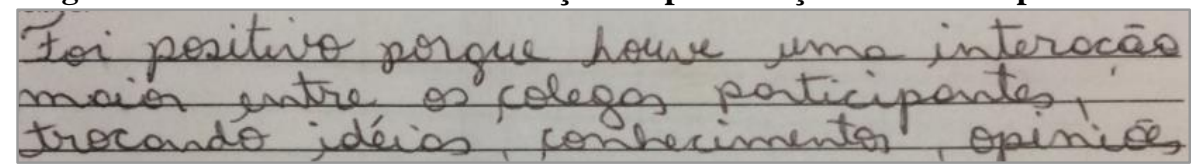

Fonte: Almeida (2017)

Também destacamos a P3Q2A na Tabela 1 abaixo, que questionava os alunos se as atividades apresentadas pelo seu grupo ajudaram a compreender o conteúdo. Esta pergunta mostrou que aproximadamente $61 \%$ da turma considerou que tais apresentações ajudou muito, o que é consideravelmente satisfatório:

Tabela 1: Percentual das respostas da Pergunta 3 do Questionário 2 dos Alunos

\begin{tabular}{lcc}
\hline \multicolumn{3}{c}{ "3) As atividades apresentadas por seu grupo the ajudaram a } \\
compreender o conteúdo?" \\
\hline ALTERNATIVAS & QUANTIDADE & $\%$ \\
a. Quase nada. & 1 & 3,2 \\
\hline b. Um pouco. & 11 & 35,5 \\
\hline c. Ajudou muito. & 19 & 61,3 \\
\hline
\end{tabular}

Fonte: Almeida (2017)

Não foram tantos os limites encontrados durante a resolução e apresentação de tarefas. Mas, talvez, a que mais tenha se destacado foi o fato de que alguns grupos tinham alunos que não colaboravam com seus colegas para a resolução das tarefas, seja em aula ou fora dela. Dessa forma, parecia que alguns se sobrecarregavam, tomando para si todas as responsabilidades do grupo. Isso pode ser pela falta de maturidade e responsabilidade por parte desses que acabavam pensando que poderiam se beneficiar através dos outros. É o que observou PMR5 ao responder a P3Q2P:

Figura 12: Limites da Resolução e Apresentação de Tarefas por PMR5

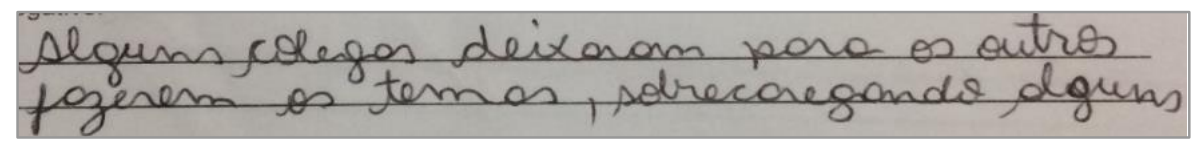

Fonte: Almeida (2017)

Além disso, mesmo planejando detalhadamente a distribuição de tarefas com o tempo disponível para a resolução, esse tempo foi insuficiente para que todos apresentassem os exercícios propostos. Dessa forma, foram aproveitados os tempos finais das demais aulas para que finalizassem suas apresentações. Isso, de certa forma, alterava o que era proposto inicialmente nas etapas da PASAI, mas permitia que todos pudessem cumprir suas atividades, já que os grupos “cobravam” que tivessem sua vez de apresentar. 
Foi interessante perceber que, diferentemente das atividades realizadas pelos seus grupos, as que eram apresentadas pelos outros grupos não foram consideradas tão relevantes como auxílio para esclarecimento de suas dúvidas. É o que observamos na coleta de dados da P2Q2A:

Tabela 2: Percentual das respostas da Pergunta 2 do Questionário 2 dos Alunos

\begin{tabular}{lcc}
\hline \multicolumn{3}{c}{ "2) As atividades apresentadas por outros grupos auxiliavam } \\
para esclarecer dúvidas?" \\
\hline ALTERNA TIVAS & QUANTIDADE & $\%$ \\
a. Quase nada & 6 & 19,4 \\
\hline b. Um pouco & 17 & 54,8 \\
c. Ajudou muito & 8 & 25,8 \\
\hline
\end{tabular}

Fonte: Almeida (2017)

Uma das possibilidades percebidas foi que, diferentemente das videoaulas, os desafios puderam ser elaborados e gravados pelo próprio professor pesquisador, através do personagem fictício "Narisvaldo", o que de certa forma tornou essa etapa criativa e realmente desafiante aos alunos.

Para os pais e alunos, foi uma forma diferente de aprendizado, como cita PMR10 e A10 ao responderem a P1Q2P e a P7Q2A, respectivamente:

Figura 13: Possibilidades da Resolução dos Desafios por PRM10

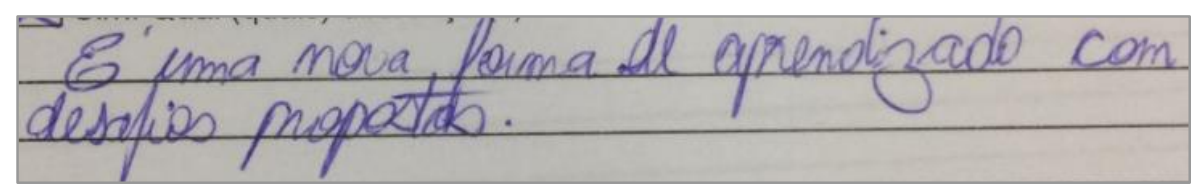

Fonte: Almeida (2017)

Figura 14: Possibilidades da Resolução dos Desafios por A1

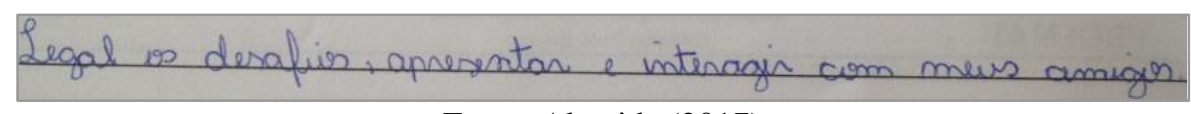

Fonte: Almeida (2017)

Outra possibilidade percebida foi a cooperatividade, que, assim como na resolução e apresentação de tarefas, eles compartilhavam de outros métodos de resolução dos desafios dos demais grupos, ajudando na compreensão dos conteúdos em estudo. Assim, havia a colaboração entre os alunos, algo que a proposta da Sala de Aula Invertida preza muito. É o que nos confirma A16 na P7Q2A: "Gostei muito dos desafios, o grupo ajudou muito no grupo (do WhatsApp)".

Durante as aulas, alguns alunos comentavam que não haviam assistido aos vídeos desafios, e consequentemente não ajudavam seus grupos nas resoluções deles. Isso, de 
certa forma, prejudicava os demais membros do grupo. É o que afirma A14 na P7Q2A como seu ponto de vista negativo:

Figura 15: Limites da Resolução dos Desafios por A14

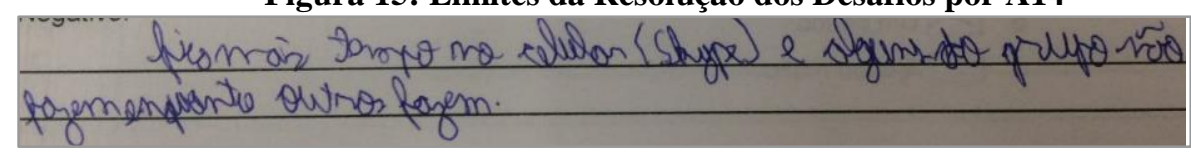

Fonte: Almeida (2017)

Observamos que não seria um limite para o aluno o uso do celular para estar em contato com os membros de seu grupo, mas sim o fato de alguns destes não colaborarem com os demais para a realização das atividades propostas.

Outro limite encontrado foi que, durante a aplicação da proposta, devido um feriado, precisamos adaptar a apresentação do desafio em aula para a elaboração de um vídeo com a resolução do mesmo, feita por pelo menos um membro do grupo. Eles enviaram o vídeo através do grupo do WhatsApp. Na percepção do professor pesquisador, o interessante foi que isso não prejudicou o aprendizado. Pelo contrário, eles foram muito criativos e fizeram vídeos editados, alguns explicados detalhadamente, com ótima postura e segurança ao resolverem os desafios.

Assim como nas atividades das etapas de motivação, os alunos participavam de forma ativa durante as aulas de diversificação das tarefas, já que de certa forma ambas as etapas são parecidas em seus fundamentos.

Ao analisarmos os trabalhos on-line, que eram respondidos através da plataforma Formulários Google, praticamente todos os alunos fizeram os exercícios e tiveram bons resultados, já que eram questões relacionadas aos conteúdos trabalhados naquela semana. Isso se tornou favorável, já que estes trabalhos funcionavam como uma revisão do conteúdo, ajudando na compreensão dos conteúdos estudados. O simples fato de ser online já não se tornava maçante aos alunos. É o que nos confirmam A2 e A25 na P7Q2A e na P5Q2A, respectivamente:

Figura 16: Possibilidades da Diversificação das tarefas por A2

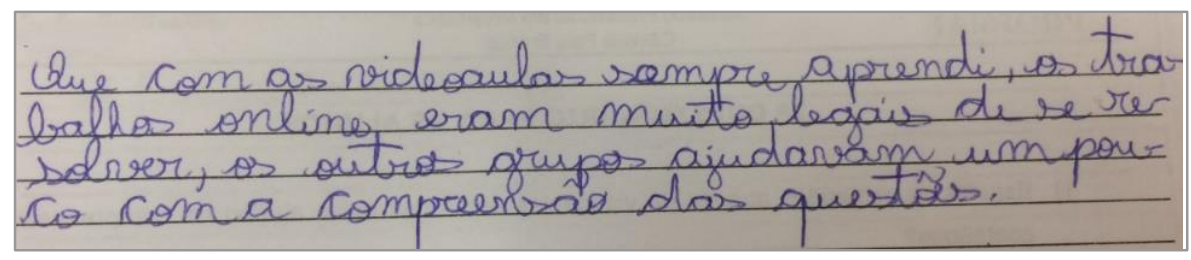

Fonte: Almeida (2017) 
Figura 17: Possibilidades da Diversificação das tarefas por A25

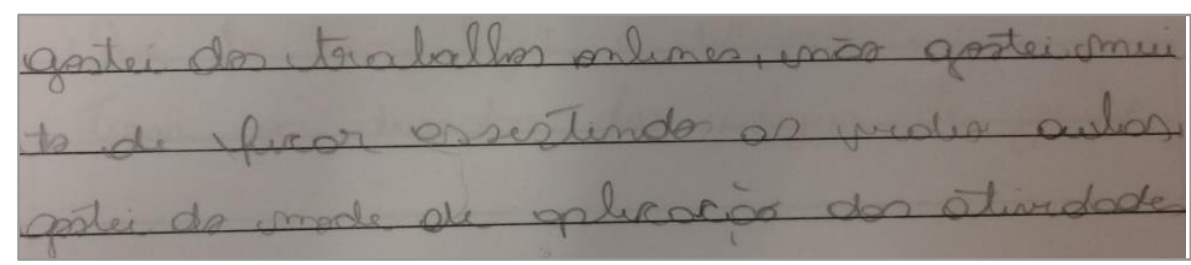

Fonte: Almeida (2017)

Durante as aulas, houve atividades em que os alunos se desafiavam uns aos outros. Esse tipo de competitividade foi considerado saudável, pois para conseguirem vencer davam o seu melhor, permitindo que fosse colocado em prática o conteúdo aprendido.

Para manter um padrão e organização, os trabalhos on-line tinham prazo para envio. Porém, percebemos que alguns alunos deixavam para resolvê-los no último dia ou acabavam esquecendo de finalizá-los. Na percepção do professor pesquisador, isso quase sempre acontecia com os mesmos alunos, o que mostra certa falta de responsabilidade e comprometimento destes alunos com seus afazeres. Podemos perceber esse descomprometimento na resposta de A16 ao responder a P5Q2A:

Figura 18: Limites da Diversificação das Tarefas por A16

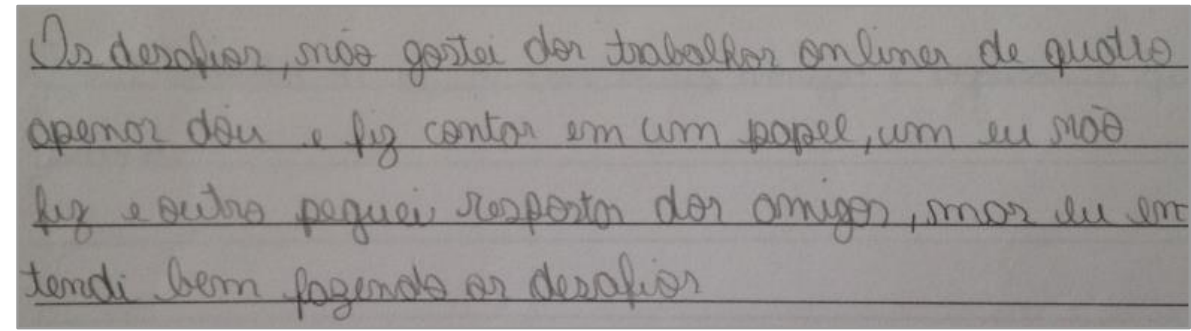

Fonte: Almeida (2017)

Acrescentamos que isso não significa que não houve mudança na postura ou comportamento por parte dos alunos durante a aplicação da proposta (até porque alguns afirmaram que compreenderam melhor os conteúdos através da PASAI), mas que, infelizmente, alguns alunos que antes da pesquisa já não cumpriam com o prazo de seus deveres, continuaram com tais dificuldades.

Como eram trabalhos individuais, e necessitava do uso da internet, alguns alunos tiveram que se adaptar a esse método, já que estavam acostumados apenas com trabalhos em papel e apenas antes da avaliação, e não semanalmente, o que acabava não agradando a todos devido a cobrança que havia. Percebemos o desagrado desta mudança nas respostas de A8 na P7Q2A: 
Figura 19: Limites da Diversificação das Tarefas por A8

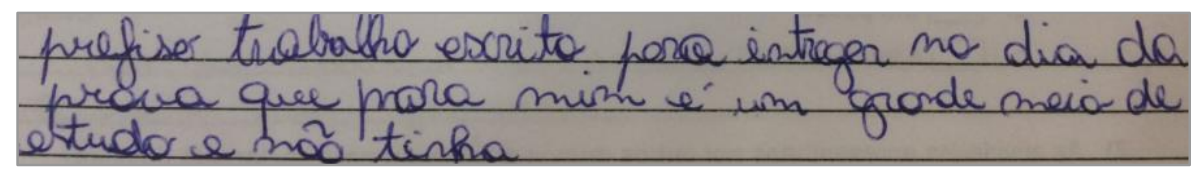

Fonte: Almeida (2017)

\section{Resultados da Pesquisa}

O quadro síntese que segue mostra cada categoria com as possibilidades e limitações encontrados após a análise.

Quadro 2: As categorias, suas possibilidades e suas limitações

\begin{tabular}{|c|c|c|}
\hline CATEGORIA & POSSIBILIDADES & LIMIT AÇÕES \\
\hline Motivação & $\begin{array}{l}\text { - Participação e interesse dos alunos; } \\
\text { - Inserção de jogos como tarefas } \\
\text { desafiadoras. }\end{array}$ & $\begin{array}{l}\text { - Tempo de aula; } \\
\text { - Problema de acesso à internet em } \\
\text { um dos dias. }\end{array}$ \\
\hline Material online & $\begin{array}{l}\text { - Tempo de aula; } \\
\text { - Participação e interação dos alunos; } \\
\text { - O uso das videoaulas; } \\
\text { - Os alunos encontravam } \\
\text { compartilhavam outras videoaulas. }\end{array}$ & $\begin{array}{l}\text { - Alguns alunos não assistiam as } \\
\text { videoaulas; } \\
\text { - Falta de informação aos pais sobre } \\
\text { a importância das videoaulas; } \\
\text { - Falta de maturidade dos alunos; } \\
\text { - As videoaulas não foram gravadas } \\
\text { pelo professor pesquisador. }\end{array}$ \\
\hline $\begin{array}{l}\text { Resolução e } \\
\text { apresentação de } \\
\text { tarefas }\end{array}$ & $\begin{array}{l}\text { - A proposta de trabalho em equipe; } \\
\text { - Aprendizagem dos alunos de forma } \\
\text { colaborativa; } \\
\text { - Dedicação e participação dos alunos; } \\
\text { - Melhor compreensão do conteúdo por } \\
\text { meio das apresentações das tarefas } \\
\text { pelos alunos. } \\
\text { - Os vídeos dos desafios puderam ser } \\
\text { gravados pelo professor pesquisador; } \\
\text { - Cooperatividade entre alunos. }\end{array}$ & $\begin{array}{l}\text { - Alguns alunos não colaboravam } \\
\text { com os colegas de seus grupos; } \\
\text { - O tempo de aula era curto para } \\
\text { cumprir o que era proposto. } \\
\text { - Alguns alunos não assistiam os } \\
\text { desafios; } \\
\text { - Adaptação e mudança de atividades } \\
\text { da proposta devido um feriado. }\end{array}$ \\
\hline $\begin{array}{c}\text { Diversificação das } \\
\text { tarefas }\end{array}$ & $\begin{array}{l}\text { - Participação ativa dos alunos; } \\
\text { - Os trabalhos on-line foram satisfatórios } \\
\text { e serviam como revisão de conteúdo, } \\
\text { além de serem instrumentos de } \\
\text { avaliação; } \\
\text { - Os alunos desafiavam-se uns aos } \\
\text { outros. }\end{array}$ & $\begin{array}{l}\text { - Falta de responsabilidade e } \\
\text { compromisso por parte de alguns } \\
\text { alunos quanto à realização dos } \\
\text { trabalhos on-line; } \\
\text { - Falta de adaptação de alguns alunos } \\
\text { em relação aos trabalhos on-line } \\
\text { semanais e à forma de avaliação. }\end{array}$ \\
\hline
\end{tabular}

Fonte: Almeida (2017)

Pudemos inferir a partir dos resultados que através do uso da metodologia da Sala de Aula Invertida, por meio da influência das TDIC inseridas nesta proposta, os alunos puderam estar mais ativos, acessando materiais antes da aula de forma on-line, realizando atividades de resolução de tarefas, seja com a mediação do professor ou colaboração dos colegas. Isso evidencia-se quando Valente afirma que através desta metodologia "o aluno estuda o material antes de ele frequentar a sala de aula, que passa a ser o lugar de aprender ativamente, realizando atividades de resolução de problemas ou projetos, discussões, laboratórios etc., com o apoio do professor e colaborativamente dos colegas (Valente, 2014, p. 1). 
Concordamos com Bergmann e Sams ao perceber que a duração da aula pôde ser reestruturada, utilizando-se mais tempo para atividades práticas, jogos de aplicação e/ou resolução de problemas dirigidos (2016, p. 12). Além disso, os alunos puderam visualizar videoaulas e vídeo-desafios enviados pelo professor, podendo pausá-las ou revê-las quando e onde quisessem, algo também evidenciado por Bergmann e Sams.

\section{Considerações finais}

Acreditamos que uma das principais contribuições do presente estudo tenha sido a elaboração da Proposta de Aplicação da Sala de Aula Invertida, além das possibilidades e das limitações inferidos a partir de sua aplicação em turmas do $8^{\circ}$ ano do Ensino Fundamental. Como foco, ficou evidente também a influência das TDIC como meios de ensino, aprendizagem e avaliação dentro das etapas da proposta. Além disso, a PASAI mostrou potencial adaptabilidade a outros conteúdos matemáticos, diferentes dos que foram usados durante a aplicação desta pesquisa, devido suas diversificadas etapas e fácil inclusão delas à realidade do professor.

Em contrapartida, percebemos que alguns pontos poderiam ser melhorados em um trabalho futuro, como exemplo citamos: divulgação de informações mais detalhada aos pais sobre o método da Sala de Aula Invertida, pois eles podem ser fundamentais para o bom desenvolvimento dos alunos; ampliação do tempo de elaboração da proposta, para que todas as videoaulas pudessem ter sido feitas pelo autor desta pesquisa; inserção de questões mais específicas relacionadas às categorias nos questionários aos pais e alunos; inserção de maior influência das Tecnologias Digitais da Informação e Comunicação (como plataformas, softwares, sites, imagens, jogos digitais, entre outros) nas etapas da proposta.

Por fim, acreditamos que os temas sintetizados, no desenvolvimento teórico da dissertação e da proposta didática construída a partir da adaptação da metodologia da Sala de Aula Invertida, possam ser úteis a professores e pesquisadores que buscam conhecer o estudo e ampliar seus conhecimentos sobre a proposta pedagógica apresentada, bem como seus resultados analisados. Em nossa opinião, estes conhecimentos constituem-se como uma possibilidade de inovação dos processos de ensino e aprendizagem, capaz de "inverter" o método tradicional, transformando o espaço "sala de aula" em um ambiente de aprendizagem mais dinâmico, interativo e tecnológico, permitindo que as tecnologias digitais auxiliem o professor a mediar o conhecimento e que os alunos sejam cada vez mais ativos no processo de ensino e aprendizagem. 


\section{Referências}

Alcântara, A. P. (s. f.). A importância da tecnologia na aprendizagem do aluno. Portal Educação. Disponível em https://siteantigo.portaleducacao.com.br/conteudo/artigos/educacao/a-importanciada-tecnologia-na-aprendizagem-do-aluno/14453. Consulta: 23/07/2020.

Almeida, B. L. C. (2017). Possibilidades e limites de uma intervenção pedagógica pautada na metodologia da sala de aula invertida para os anos finais do ensino fundamental [Dissertação de Mestrado, Universidade Tecnológica Federal do Paraná]. Repositório da UTFPR.

Azevedo, F. (2010). Manifestos dos pioneiros da Educação Nova (1932) e dos educadores 1959. Editora Massangana.

Bardin, L. (2006). Análise de conteúdo. Tradução L. A. Rego; A. Pinheiro. Lisboa: Edições 70, (Obra original publicada em 1977).

Bicudo, M. A. V. (1999). Pesquisa em Educação Matemática: Concepções e Perspectivas. São Paulo: Ed. Unesp, p. 25-26.

Bergmann, J. \& Sams, A. (2016). Sala de Aula Invertida: uma metodologia ativa de aprendizagem. Tradução Afonso Celso da Cunha Serra - $1^{\mathrm{a}}$ ed. Rio de Janeiro. LTC.

Casagrande, R. B. (2008). A importância da internet no contexto escolar. Crisciúma-SC.

Costa, A. P. (2011). O Uso de Recursos Tecnológicos por Professores de Matemática do Ensino Médio. In. V Colóquio Internacional de Políticas e Práticas Curriculares.

Colossi, N., Consentino, A. \& Queiroz, E. G. (2001). Mudanças no Contexto do Ensino Superior no Brasil: Uma Tendência ao Ensino Colaborativo. FAE, v. 4, n. 1, 4958.

Da Costa, P. \& Bianchini, D. (2008). Caracterização da demanda futura de usuários da internet no Brasil: uma contribuição para o desenvolvimento de políticas governamentais de inclusão digital e acesso à internet. Revista de Gestão da Tecnologia e Sistemas de Informação, São Paulo, v. 5, n. 1, p. 135-162, jan./abr.

Damaceno, L. M. (2013). A aula de Matemática em vídeo e as Redes Sociais como recursos didáticos: uma experiência com a disciplina Estatística no Ensino Médio Inovador [Dissertação de Mestrado, Universidade Estadual do Sudoeste da Bahia]. Repositório PROFMAT.

Estrela, A. \& Nóvoa, A. (org.). (1993). Avaliações em Educação: Novas Perspectivas. Porto Editora.

Fernandes, D. (2007). A avaliação das aprendizagens no Sistema Educativo Português. Educação e Pesquisa, 33(3), 581-600.

Francisco, W. C. (s. f.). A utilização de novas metodologias. Brasil Escola. Disponível em http://educador.brasilescola.uol.com.br/estrategias-ensino/a-utilizacao-novasmetodologias.htm. Consulta: 23/07/2020.

Freitas, V. J. (2015). A aplicabilidade da flipped classroom no ensino de física para turmas da $1^{a}$ série do ensino médio. UFES, IF, 149f. 
Gadotti, M. (2000). Perspectivas atuais da educação. Ed. Artes Médicas.

Imme, A. (2020, 21 de janeiro). Ranking das redes sociais: as mais usadas no Brasil e no mundo, insights e materiais gratuitos. Resultados Digitais. Disponível em https://resultadosdigitais.com.br/blog/redes-sociais-mais-usadas-no-brasil/. Consulta: 23/07/2020.

Machado, J. A. S. (2005). Difusão do Conhecimento e Inovação - o acesso aberto a publicações científicas. In: BAUMGARTEN, M. (Org.). Conhecimentos e redes: sociedade, política e inovação. Editora da UFRGS.

Moran, J. M. (2015). Mudando a educação com metodologias ativas. In: Souza, C. A. \& Torres-Morales, O. E. (Orgs.). Convergências midiáticas, educação e cidadania: aproximações jovens. Ponta Grossa: UEPG, (Mídias Contemporâneas, v. 2). p. 1533.

Moretto, T. (2015, 17 de novembro). Opinião: Novas metodologias para nossos professores. Instituto Claro. Disponível em https://www.institutoclaro.org.br/educacao/nossas-novidades/opiniao/novasmetodologias-para-nossos-professores/. Consulta: 23/07/2020.

Oliveira, V. (2016, 25 de fevereiro). Novas metodologias usam situações reais para formar professores. Porvir (org.). Disponível em http://porvir.org/novas-metodologiasusam-situacoes-reais-para-formar-professores/. Consulta: 23/07/2020.

Paiva, T. (2016, 24 de agosto). Como funciona a sala de aula invertida?. Carta Educação. Disponível em http://www.cartaeducacao.com.br/reportagens/como-funciona-asala-de-aula-invertida/. Consulta: 23/07/2020.

Penteado, M. G. \& Borba, M. C. (2003). Informática e Educação Matemática. Belo Horizonte: Autêntica.

Perez, L. A. (2015). Um estudo sobre o uso de avaliações apoiadas pelas tecnologias [Dissertação de Mestrado, ICM-USP/São Carlos]. Repositório USP. 105824/publico/LeonardoAnselmoPerez_revisada.pdf

Sanches, C. (2015, 24 de julho). Metodologias de ensino: ontem e hoje. ARedeEduca. Disponível em http://www.arede.inf.br/metodologias-de-ensino-ontem-e-hoje/. Consulta: 23/07/2020.

Souza, M. G. $O$ uso da internet como ferramenta pedagógica para os professores do ensino fundamental [Monografia (TCC), Universidade Estadual do Ceará]. Repositório UAB/UECE.

Thiollent, M. (2011). Metodologia da Pesquisa-ação. Cortez.

Valente, J. A. (2014). Blended learning e as mudanças no ensino superior: a proposta da sala de aula invertida. Educar em Revista,4, 79-97.

Varela-Ordorica, S., \& Valenzuela-González, J. (2020). Use of Information and Communication Technologies as a Transversal Competence in Teacher Training. Revista Electrónica Educare, 24(1), 1-20.

Velloso, F. C. (2004). Informática: conceitos básicos (7. a ed.). Rio de Janeiro: Campus.

Vieira, Z. N. L. (2006). A informática na educação. Rio de Janeiro. 
Autores

Braian Lucas Camargo Almeida

Doutorando em Educação Matemática - PPGECM/UFPR. Atualmente sou professor orientador no curso de Especialização em Práticas Educacionais em Ciências e Pluralidade, promovido pela UTFPR Câmpus Dois Vizinhos, e é professor Substituto do Magistério Superior na UTFPR - Campus Dois Vizinhos/PR, atuando nas disciplinas relacionadas ao

Cálculo, Geometria Analítica e Álgebra Linear e Matemática Discreta. E-mail:

braian_almeida@hotmail.com

Janecler Aparecida Amorin Colombo

Doutorado em Educação Científica e Tecnológica pela Universidade Federal de Santa

Catarina (2008). Atualmente é professora Nível Associado II no Departamento de Matemática, da Universidade Tecnológica Federal do Paraná - Campus Pato Branco. Atuando principalmente nos seguintes temas: formação de professores, representação semiótica, resolução de problemas, metodologias de ensino, processos de ensino e aprendizagem da matemática. E-mail janecler.aac@gmail.com 